\title{
A Novel of Hybrid Magnet Engine Valve Actuator Using Shorted Turn for Fast Initial Response
}

\author{
DucThuan Vu and Hwang Pyung
}

\begin{abstract}
A variable valve timing (VVT) can improve fuel efficiency, reduce $\mathrm{CO} 2$ emission and increase torque output. To achieve VVT in internal combustion engine, new devices such as mechanical, hydraulic, motor-driven and electromagnetic actuator have been developed in past years to replace the conventional camshaft valve train system used currently. Among these, the electromagnetic actuator using solenoids is the most advance system to provide the most flexibility to valve timing, but it has critical drawback of high power consumption. This paper presents a novel design of Hybrid Magnet Engine Valve Actuator (HMEVA) using shorted turn. A shorted turn is placed into existing design in order to reduce the inductance of coil and improve the initial response. Dynamic finite element analysis using commercial electromagnetic solver "MAXWEL" is performed to simulate the improvement of dynamic characteristic of model.
\end{abstract}

Index Terms - Variable valve timing (VVT), Hybrid magnet engine valve actuator (HMEVA), shorted turn, finite element analysis, permanent magnet (PM), electromagnet (EM).

\section{INTRODUCTION}

Variable valve timing (VVT) is key technology to overcome a conventional camshaft engine valve system. VVT allows the cam profile to change, which results in greater efficiency and power. Valve events are controlled independently of camshaft rotation. As a result, fuel consumption may be reduced up to $15 \%$, torque output is enhanced in wide range of engine speed, and $\mathrm{CO} 2$ emission may be decreased up to $15 \%$ [1], [2].

Some of the devices developed in the past years to achieve variable valve timing include mechanical, hydraulic, motor-driven, and electromagnetic actuators. The simplest VVT systems advance or retard the timing of the intake or exhaust valves like Mazda's S-VT. On the other hand Honda's VTEC switches between two sets of cams at a certain engine RPM. However, these systems add complexity, and there is not much improvement to torque [3]. Another technology altogether uses small electric motor to control valve motion [4]. But this technology is still very near the beginning stage of development. The most advanced system is the hybrid magnet engine valve actuator using $\mathrm{PM} / \mathrm{EM}$ (permanent/electromagnet).

Manuscript received July 17, 2012; revised August 24, 2012

This work was supported by the Center for Green Car Parts, Ministry of Knowledge Economy and Yeungnam University.

Duc Thuan Vu is Ph.D candidate of Mechanical Engineering Departmen in Yeungnam University, Gyeongsan, South Korea (e-mail: vudthuan@gmail.com).

Pyung Hwang is the Professor of Mechanical Engineering at School of Mechanical Engineering, Yeungnam University, Gyeongsan, South Korea (e-mail: phwang@yu.ac.kr).
Fig. 1 shows the schematic diagram of HMEVA the main operation principle is mass-spring oscillation and variable valve timing is achieved by control of voltage applied to the coils [5].

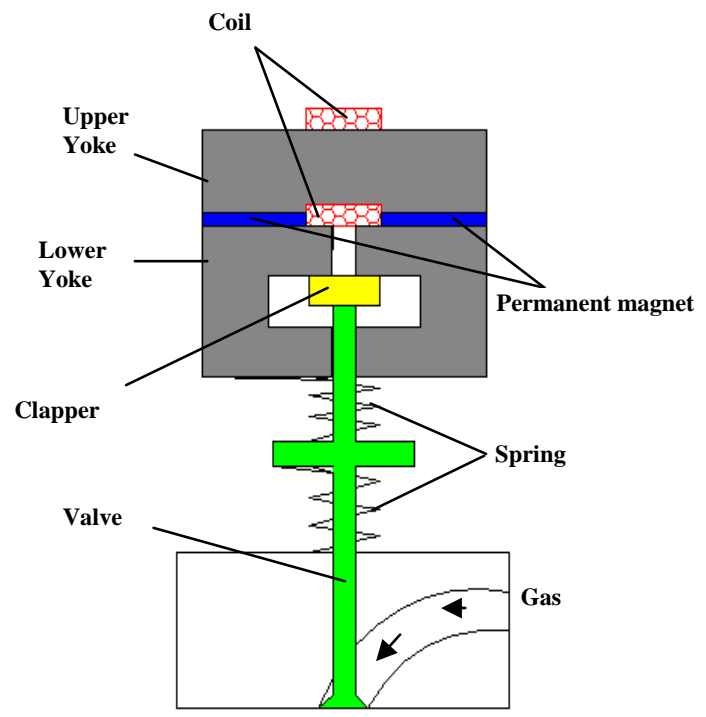

Fig. 1. Schematic diagram of conventional HMEVA

The duration of valve events and phase between the intake valve and exhaust valve are very flexible [6]. Several automotive manufactures experimented with conventional HMVEA design. However, these conventional types of actuator suffer the inherent problem of high-energy consumption for operation. The significant cause for the high-energy consumption is due to inductance of coil. Therefore, in this paper, a new design of HMEVA using shorted turn is introduced. The purpose of proposed actuator is in order to reduce the inductance of coil and improve the initial response when it is driven by voltage. To characterize the performance of the proposed actuator, the equivalent magnetic circuit model of newly design is developed for mathematical analysis and dynamic performance is verified to perform finite-element analyses using a commercial FEM solver, Maxwell.

\section{Structure And Operating Principle of The PROPOSED ACTUATOR}

The structure and operating principle of the newly proposed actuator are similar to the conventional HMEVA. To reduce the inductance, the upper yoke is inserted a thin copper plate, as shown in Fig. 2. This thin copper plate is called by shorted turn which helps the current of coil to rise quickly by reducing inductance when the voltage is applied. As opposed to the conventional actuator, in our design when 
a voltage is applied to the coil of actuator, the flux in the magnetic circuit induces a high current in the copper sleeve in such a way as to retard the increase of magnetic flux. In result, the inductance of coil is reduced and current rise quickly [7].

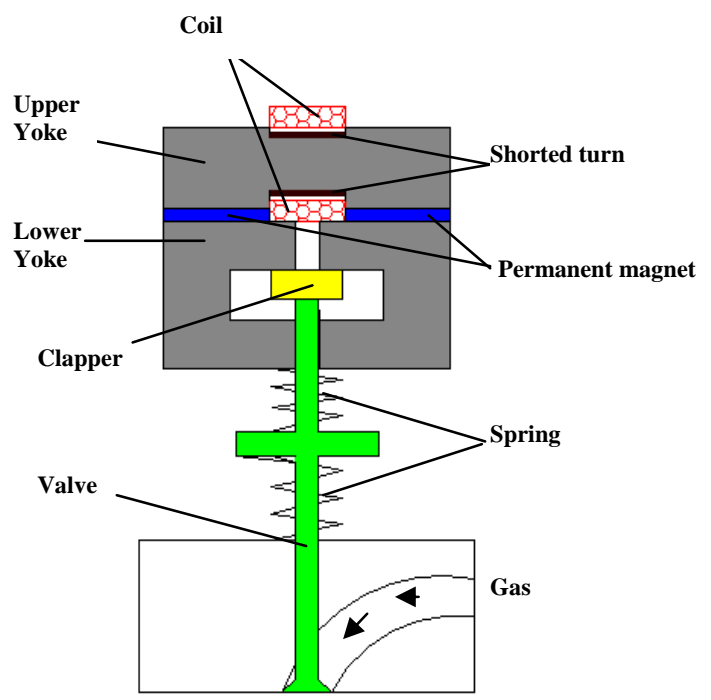

Fig. 2. Schematic diagram of proposed HMEVA

\section{DYNAMIC FINITE ELEMENT ANALYSIS}

To simulate the actuator, finite-element models (FEM) were created and dynamic finite-element analysis was performed using the nonlinear FEM solver Maxwell. The newly proposed actuator is composed of three subsystems: a mechanical system, an electrical system, and a magnetic system, which are all coupled to each other.

The magnetic subsystem is governed by equation (1). The nonlinear magnetic B-H properties of material-180 steel were assigned to yokes and the clapper, and the magnetic properties of $\mathrm{NdFe} 30$ were assigned to the permanent magnet. Table I shows the specifications of the NdFe 30 permanent magnet.

TABLE I: THE MAGNETIC PROPERTIES OF NDFE30 PM

\begin{tabular}{cc}
\hline \hline Symbols & Magnitude \\
\hline $\mathrm{B}_{\mathrm{r}}(\mathrm{T})$ & 1.1 \\
$\mathrm{H}_{\mathrm{c}}(\mathrm{A} / \mathrm{M})$ & $-8.38 \times 10^{5}$ \\
$\mathrm{M}_{\mu}$ & 1.0445730167 \\
\hline \hline
\end{tabular}

$$
\nabla \times\left(\frac{1}{\mu} \nabla \times \vec{A}_{z}\right)=\vec{J}_{e x t}+\frac{1}{\mu} \nabla \times \vec{M}
$$

Boundary condition $\overrightarrow{A_{z}}=0$

where $\overrightarrow{A_{z}}$ is the magnetic vector potential; $\overrightarrow{J_{e x t}}$ is the external current density; $\mu$ is the permeability of the material; $\vec{M}$ is the magnetization of permanent magnet

The mechanical system is governed by equation (2). The moving mass clapper and the stiffness of springs are specified. The moving mass includes clapper, engine valve, keeper and a fraction of springs. Table II shows the specifications of the mechanical subsystem.

$$
m \ddot{x}+c \dot{x}+2 k x=F_{\text {magnetic }}
$$

Initial condition $x(0)=-3.95(\mathrm{~mm}), x(0)=0$ where $m$ is the moving mass; $x$ is the displacement of armature; $k$ is the spring stiffness; $c$ is the damping coefficient of air; $F_{\text {magnetic }}$ is the magnetic force in air gap

TABLE II: PhySICAL PROPERTIES OF HMEVA SYSTEM

\begin{tabular}{ccc}
\hline Symbols & Quantity & Magnitude \\
\hline $\mathrm{k}$ & Spring stiffness & $292(\mathrm{kN} / \mathrm{m})$ \\
$\mathrm{m}$ & Moving mass & $0.136(\mathrm{~kg})$ \\
$\mathrm{c}$ & Damping coefficient & 2.8182 \\
$\mathrm{~N}$ & Number of turns & $250($ turns $)$ \\
\hline \hline
\end{tabular}

The electrical subsystem consists of the coil, shorted turn, voltage power supply and toggle switch. The electrical subsystem is described by equation (3)

$$
\frac{d \lambda(i, x)}{d t}+R i=V
$$

Initial condition $\mathrm{i}(0)=0$

where $\lambda$ is the flux linkage; $i$ is the coil current; $R$ is the resistance of coil

The 2-D dynamic finite-element model, which consists of 40,000 triangle elements, was created to assist in modeling these coupled systems. The dynamic motion of the clapper from the lower end to the upper end of stroke was simulated. The analysis is performed with 10 microsecond time steps over a period of 4 milliseconds. The magnetic forces exerting on the moving clapper was computed through virtual work principle method [8].

\section{Results AND Discussions}

Fig. 3 and 4 show the magnetic flux line of conventional actuator and new design actuator at two positions during motion. Fig. 3(a) and 4(a) show the magnetic flux from the permanent magnet holding the clapper at lower end position of stroke. (a)

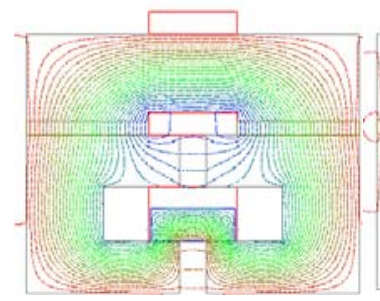

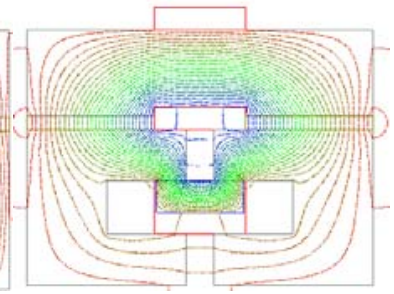

(b)
Fig. 3. Magnetic flux line of conventional actuator (a) at the lower position; (b) at the upper position

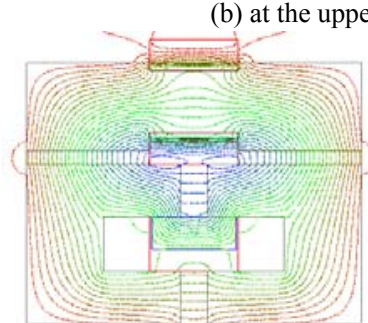

(a)

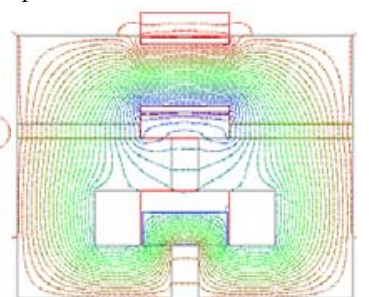

(b)
Fig. 4. Magnetic flux line of proposed actuator (a) at the lower position; (b) at the upper position

Fig. 3(b) and 4(b) show the magnetic flux line when clapper is located at upper, latched position.

Fig. 5 shows the voltage command to the electromagnetic coil of two actuators. The positive voltage creates a magnetic 
flux in the opposite direction of permanent magnet flux to release the armature while negative voltage, which is reversely controlled from the neutral position of stroke, creates a flux in the same direction as permanent magnet flux to overcome the spring force catch armature.

Comparing the conventional actuator and new design using shorted turn, the high voltage of $110(\mathrm{~V})$ is required by the conventional actuator to release the armature as illustrated by the Fig. 5(a) while in the proposed actuator only $7(\mathrm{~V})$ is needed to perform the same work as shown in Fig. 5(b). This shows clearly that the new design is more efficient in term of energy consumption. This significant energy reduction is due to the shorted turn is placed in new design. The shorted turn made the current of coil to rise quickly by reducing inductance when the voltage is applied

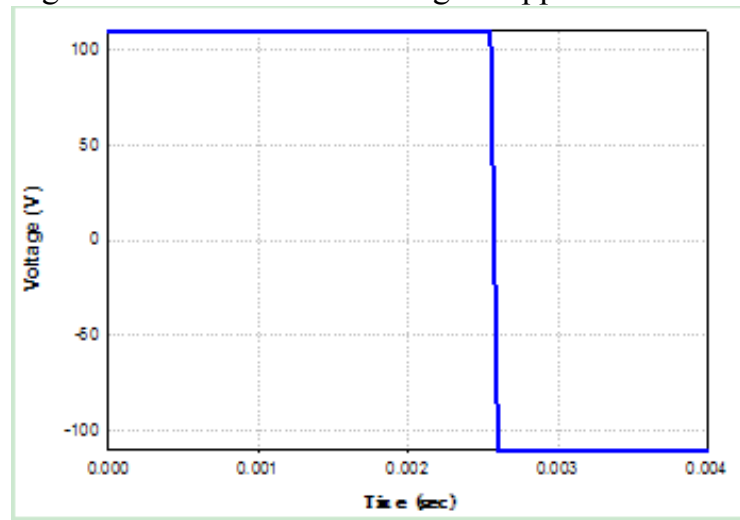

(a)

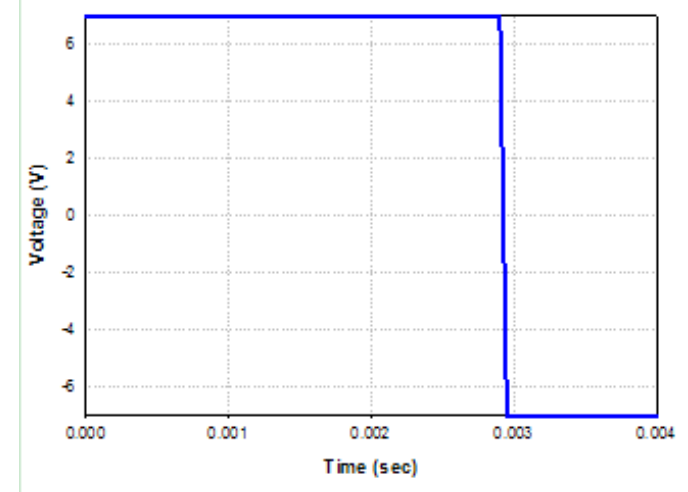

(b)

Fig. 5. Profile of the voltage command to the electromagnetic coil (a) conventional actuator; (b) proposed actuator

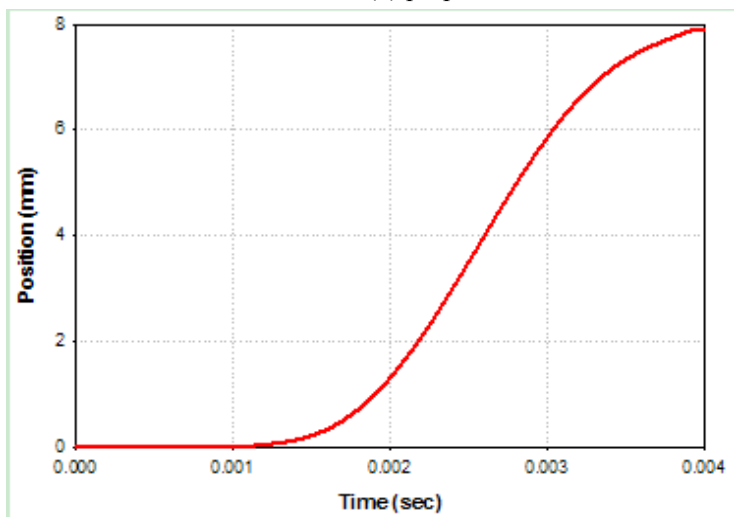

Fig. 6. Profile of position versus time of conventional actuator

Fig. 6 and 7 show the profiles of position versus time of two actuators, conventional and proposed, respectively.

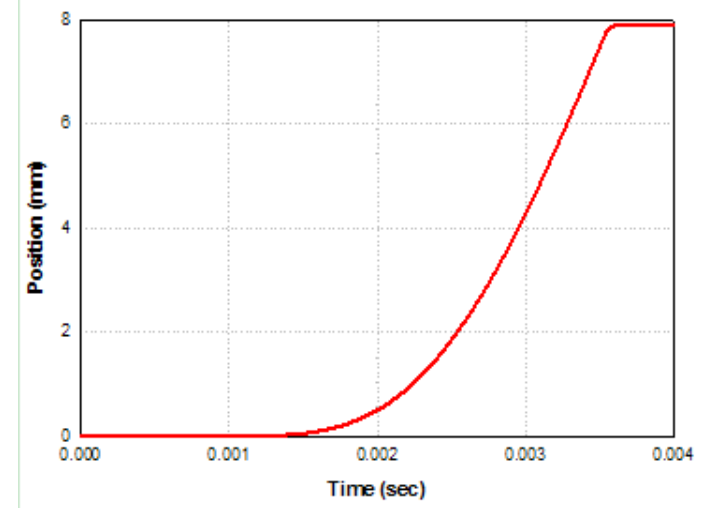

Fig. 7. Profile of position versus time of proposed actuator

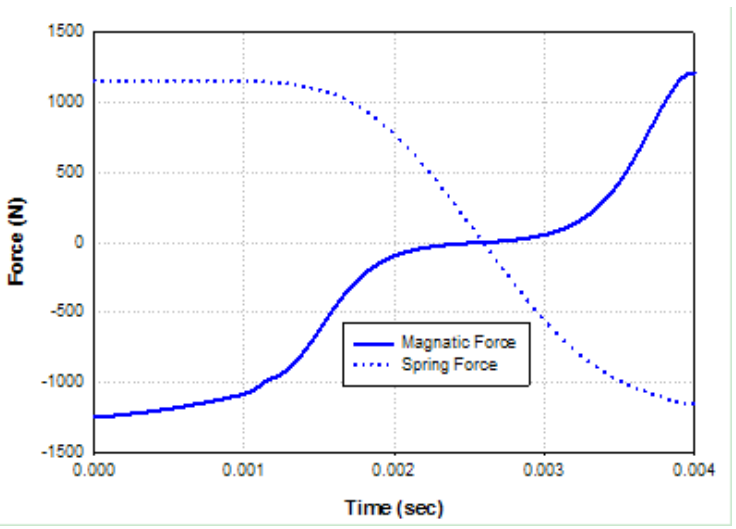

Fig. 8. Profile of Forces versus time of conventional actuator

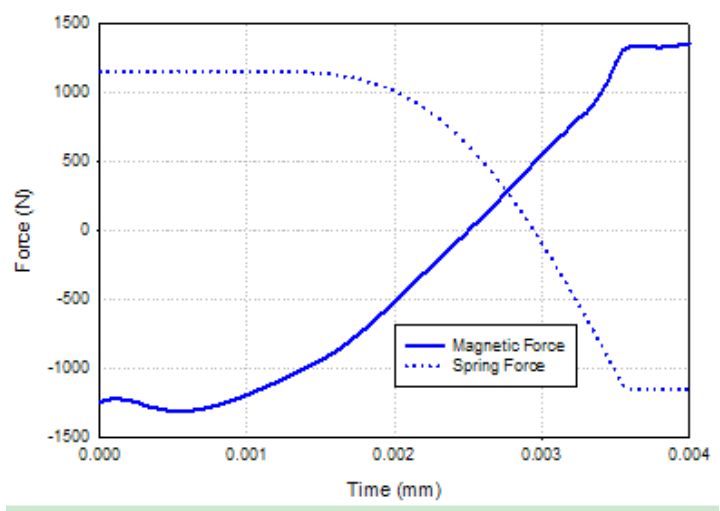

Fig. 9. Profile of forces versus time of proposed actuator

Fig. 8 and 9 show the profile of magnetic force and spring force of conventional actuator and proposed actuator that moves from the lower end to upper end positions.

\section{CONCLUSIONS}

New design of hybrid magnet engine valve actuator, using shorted turn, is proposed to overcome the inherent drawbacks of large power consumption in conventional type. To evaluate the performances of the proposed system and compare with conventional system, the simulations using FE analyses were performed. The results show that the new system with shorted turn has much smaller power consumption compared with conventional system without shorted turn and it is suitable for application in an internal combustion engine. 


\section{ACKNOWLEDGMENT}

This work was supported by the Center for Green Car Parts, Ministry of Knowledge Economy and Yeungnam University.

\section{REFERENCES}

[1] P. Barkan and T. Dresner, "A Review of Variable Valve Timing Benefits and Modes of Operation," SAE Technical Paper Series, pp. 891676, 1989.

[2] M. Pischinger, M. Salber, F. Staay, H. Baumgarten, and H. Kemper, "Benefits of the Electromechanical Valve Train in Vehicle Operation," SAE Technical Paper Series, pp. 1223, 2000.

[3] M. Hamazaki and T. Hosaka, "Development of the Variable Valve Timing and Lift (VTEC) engine for Honda NSX," SAE Technical Paper Series, pp. 910008, 1991.

[4] W. S. Chang, T. A. Parlikar, M. D. Seeman, D. J. Perreault, J. K. Kassakian, and T. A Keim, "A New Electromagnetic Valve Actuator," IEEE Transactions on Power Electronics in Transportation, pp. 109-118, 2002

[5] J. Kim and D. K. Lieu, "Designs for a New, Quick-Response, Latching Electromagnetic Valve," IEEE, pp. 1773-1779, 2005.

[6] G. Sugimoto, H. Sakai, A. Umenomoto, Y. Shimizu, and H. Ozawa, "Study on Variable Valve Timing System Using Electromagnetic Mechanism," SAE Technical Paper Series, pp. 1896, 2004.
[7] H. D. Chai, "Electromechanical Motion Devices," San Jose State University.

[8] J. Kim and D. K. Lieu, "A New Electromagnetic Engine Valve Actuator with Less Energy Consumption for Variable Valve Timing," Mechanical Science and Technology, pp. 602-606, 2007.

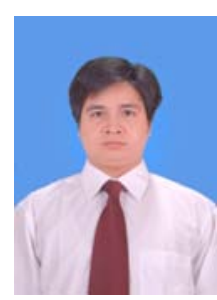

Duc Thuan Vu was born in Hungyen, Vietnam, in 1981. $\mathrm{He}$ received the B.Sc. and M.Sc. degrees in Mechanical Engineering from Hanoi Agriculture University, Hanoi, Vietnam, in 2003 and 2008, respectively. He is currently working toward the Doctor degree in Mechanical Engineering at Yeungnam University. His research interest includes the loss analysis and heat transfer of permanent magnet motor using for electric vehicle.

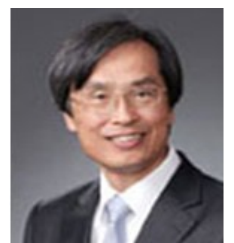

Pyung Hwang received B.Sc. in Mechanical Design \& Production Engineering, M.Sc. and Ph.D. degrees from Seoul National University in 1979, 1981 and 1989, respectively. Dr. Hwang is currently a Professor at the School of Mechanical Engineering at Yeungnam University, Korea. His research interests include Tribology and Rotordynamics. 